\title{
Use of laboratory testing for genital chlamydial infection in Norway
}

\author{
Preben Aavitsland
}

\begin{abstract}
Objective-To assess the use of laboratory tests for genital chlamydial infection in Norway.

Design-Questionnaire survey of general practitioners' practice in chlamydial testing, retrospective survey of laboratory records, 1986-91, and prospective study of testing in one laboratory during four weeks.

Setting-All 18 microbiological laboratories in Norway ( $4 \cdot 2$ million population), including one serving all doctors in Vestfold county ( $0 \cdot 2$ million population). Subjects-302 general practitioners.

Main measures-GPs' routine practice, methods used for testing, 1986-91, and sex specific and age group specific testing in 1991.
\end{abstract}

Results-201(69\%) GPs replied to the questionnaire: $101(51 \%)$ would test all women younger than 25 years at routine pelvic examination, $107(54 \%)$ all girls at first pelvic examination, $131(66 \%)$ all pregnant women, and $106(54 \%)$ all men whose female partner had urogenital complaints. Nationwide in 1986, 122000 tests were performed $(2.9$ per 100 population); $10 \%$ were positive and $51 \%$ were cell culture tests. In 1991, 341000 tests were performed $(8.0$ per 100 population); $4 \cdot 5 \%$ were positive and $15 \%$ were cell culture tests. 13184 tests were performed in Vestfold in 1991 (6.6 per 100 population). The age group specific rates (per 100 population) among women were: age $15-19$ years, $22 \cdot 0(95 \%$ confidence interval $18 \cdot 2$ to $25 \cdot 8)$; 20-24 years, $47 \cdot 2(42 \cdot 1$ to $52 \cdot 3) ; 25-29$ years, $42 \cdot 3(37 \cdot 1$ to $47 \cdot 5)$; $30-34$ years, $29 \cdot 8(25 \cdot 4$ to $34 \cdot 2)$; and 35-39 years, $12 \cdot 5(9 \cdot 5$ to $15 \cdot 5)$.

Conclusions-GPs use liberal indications for testing. The dramatic increase in testing, especially by enzyme immunoassays, in populations with a low prevalence of infection results in low cost effectiveness and low predictive value of positive tests, which in women over 29 years is estimated as $17-36 \%$.

Implications-Doctors should be educated about the limitations of enzyme immonoassays in screening low prevalence populations, and laboratories should apply a confirmatory test to specimens testing positive with such assays.

(Quality in Health Care 1993;2:91-95)
Genital chlamydial infestion in women is associated with infertility, chronic abdominal pain, and ectopic pregnancy. ${ }^{12}$ Three quarters of all cases of genital chlamydial infection in women are believed to be asymptomatic. ${ }^{34}$ Hence, in most cases the infection is probably diagnosed through routine testing rather than clinical testing. In Norway most of this testing takes place in general practice as there are only three genitourinary medicine clinics and 60 gynaecologists, who practise privately.

Cell culture is regarded as the standard for chlamydial testing. ${ }^{5-7}$ The method has a $100 \%$ specificity, but a transport time from the general practitioner (GP) to the laboratory of less than 24 hours is crucial for survival of the chlamydias and thus for test sensitivity. For most GPs in Norway this prohibits the use of the method. Enzyme immunoassays (EIAs) detect chlamydial antigens, not viable chlamydias, and are therefore independent of transport times.

A recent study in Trondheim, Norway, evaluated against cell culture the performance of two EIAs curently being used in Norway (Chlamydiazyme, Abbot Laboratories; Ideia, Celltech). ${ }^{8}$ A specificity of $95-99 \%$ (table 1) agrees with performances observed in several other studies of these assays. ${ }^{56}$

Norwegian microbiologists have reported that chlamydial tests make up a rapidly increasing share of their laboratories' workload. ${ }^{8}$ Large scale screening for genital chlamydial infection seems to have been instituted without any official guidelines. The purpose of this study was to assess the present use of testing for chlamydial infection in Norway. I chose to survey GPs directly to obtain an estimate of their routine practice. The laboratories provided the total number of tests performed, the methods used, and the distribution of these tests by sex and age of the patient.

\section{Subjects and methods}

SURVEY OF GENERAL PRACTITIONERS

I sent a structured questionnaire to every 10 th $(n=302)$ GP on the alphabetical membership list of the Norwegian Medical Association, followed by a reminder two weeks later. The GPs were to indicate if they routinely performed a chlamydial test on "all," "most," "some," or "none" of asymptomatic patients in the following categories: women younger than 25 years at routine pelvic examinations during visits for family planning, young girls at their first pelvic examination, pregnant women 
at one of their antenatal controls, and men who stated that their female partner had unspecified urogenital complaints. The GPs' routines for treatment of genital chlamydial infections ${ }^{9}$ and notification of partners ${ }^{10}$ have been reported from the same survey.

NATIONWIDE LABORATORY SURVEY

I sent a questionnaire to all the 18 medical microbiological laboratories in Norway, requesting information on the methods they used for chlamydial testing, the number of genital specimens tested, and the number of positive test results from 1986 to 1991 . The laboratories were asked to count multiple specimens from the same patients as one specimen.

VESTFOLD CENTRAL LABORATORY STUDY

To obtain the age and sex distribution of the tested patients in all the laboratories would be a formidable task. For simplicity I chose to record these data in a randomly selected four week period in only one laboratory. Vestfold Central Laboratory was chosen because it serves all hospitals and doctors within Vestfold county but no doctor outside the county. Sex and age of the patients who received a chlamydial test were registered by using the laboratory's computerised database of incoming samples. By using census data the distribution of tests could be converted to sex specific and age group specific rates for chlamydial testing. The laboratory used the Chlamydiazyme assay.

ESTIMATES OF FALSE POSITIVE RATES

The predictive value of a positive diagnostic test (positive predictive value, PPV) is related to the prevalence $(P)$ of the condition in the population; the specificity of the test $(\mathrm{Sp})$; and, to a lesser degree, the sensitivity of the test $(\mathrm{Sn})$ by the following equation ${ }^{11}$ :

$\mathrm{PPV}=\frac{\mathrm{Sn} \times \mathrm{P}}{(\mathrm{Sn} \times \mathrm{P})+((1-\mathrm{Sp}) \times(1-\mathrm{P}))}$

The false positive rate (FPR) denotes the percentage of the positive test results that are false positive and is given by the equation:

$\mathrm{FPR}=1-\mathrm{PPV}$

To obtain estimates of PPV and FPR that were independent of the Vestfold survey I used the test performances ( $\mathrm{Sn}$ and $\mathrm{Sp}$ ) from the Trondheim study (table 1) and the prevalences ( $P$ ) of chlamydial infection (as determined by cell culture) in different age

Table 1 Performance of enzyme immunoassays (Chlamydiazyme, Ideia) for detecting Chlamydia trachomatis in one Norwegian study $(n=349)^{8}$

\begin{tabular}{|c|c|c|c|c|}
\hline & \multicolumn{2}{|c|}{ Chlamydiazyme } & \multicolumn{2}{|c|}{ Ideia } \\
\hline & $\%$ & $95 \% C I$ & $\%$ & $95 \% C I$ \\
\hline $\begin{array}{l}\text { Sensitivity } \\
\text { Specificity } \\
\text { Prevalence (based on cell culture) } \\
\text { Prevalence (based on test) }\end{array}$ & $\begin{array}{r}81 \cdot 3 \\
96 \cdot 4 \\
4 \cdot 6 \\
7 \cdot 2\end{array}$ & $\begin{array}{c}62 \cdot 1 \text { to } 100 \\
94 \cdot 4 \text { to } 98 \cdot 4 \\
2 \cdot 4 \text { to } 6 \cdot 8 \\
4 \cdot 5 \text { to } 9 \cdot 9\end{array}$ & $\begin{array}{r}93 \cdot 8 \\
98 \cdot 5 \\
4 \cdot 6 \\
5 \cdot 7\end{array}$ & $\begin{array}{c}81 \cdot 9 \text { to } 100 \\
97 \cdot 2 \text { to } 99 \cdot 8 \\
2 \cdot 4 \text { to } 6 \cdot 8 \\
3 \cdot 3 \text { to } 8 \cdot 2\end{array}$ \\
\hline
\end{tabular}

groups of all the women who had a legal abortion in Oslo in 1991. The prevalences were $5.9 \%$, women aged $<20$ years; $6.3 \%$, 20-24 years; $2 \cdot 7 \%, 25-29$ years; and $0.9 \%$, $>29$ years (G Baldvinsdottir, unpublished observations).

\section{Results}

ROUTINE PRACTICE

Two hundred and one GPs returned completed or partly completed questionnaires. Eleven questionnaires were returned unanswered because the doctor was abroad or no longer practising. The adjusted response rate was thus $69 \%$. Half of the GPs stated that they would test all patients in all four categories (table 2). The GPs' routine practice varied only slightly between the categories. In pairwise comparisons between the categories there were no significant differences $\left(\chi^{2}\right.$ test for trend).

TEST METHODS

All 18 laboratories responded; one laboratory provided only estimates of the number of tests during 1986-9, and these estimates were included in the total (table 3). Most laboratories used only one method for chlamydial testing, and EIAs have become the most used tests. In 1986, $49 \%$ of chlamydial tests were performed by non-culture methods; in 1991 the percentage had increased to $85 \%$. Only one laboratory still used cell culture for all chlamydial tests. Testing activity increased from 2.9 tests per hundred population in 1986 to 8.0 per hundred in 1991 . The rate of positive tests decreased steadily from 1986 .

SEX SPECIFIC AND AGE SPECIFIC TESTING RATES

In all, 13184 specimens were tested for Chlamydia trachomatis in Vestfold county in

Table 2 Routine practice of Norwegian general practitioners in testing for chlamydial infection

\begin{tabular}{lc}
\hline Response & No (\%) of GPs \\
\hline \multicolumn{1}{c}{ Women younger than } & 25 years at routine pelvic examination \\
All & $101(51)$ \\
Most & $50(25)$ \\
Some & $40(20)$ \\
None & $8(4)$ \\
\hline Total & $199(100)$ \\
\hline & Young girls at first pelvic examination \\
All & $107(54)$ \\
Most & $43(22)$ \\
Some & $39(20)$ \\
None & $11(6)$ \\
\hline Total & $200(100)$ \\
\hline & Pregnant women at antenatal control \\
All & $131(66)$ \\
Most & $24(12)$ \\
Some & $34(17)$ \\
None & $10(5)$ \\
\hline Total & $199(100)$ \\
\hline & Men whose female partner has urogenital complaints \\
All & $106(54)$ \\
Most & $44(23)$ \\
Some & $40(21)$ \\
None & $5(3)$ \\
\hline Total & $195(100)$ \\
\hline &
\end{tabular}


Table 3 Number of tests for genital chlamydial infection, methods used, and rates of positive tests in Norway 1986-91. Actual numbers are thousands

\begin{tabular}{lcccccc}
\hline Year & \multicolumn{5}{c}{ No (\%) of tests performed by: } \\
\cline { 4 - 6 } & Total no & $\begin{array}{c}\text { No per 100 } \\
\text { population }\end{array}$ & Cell culture & ELA & Other & $\begin{array}{c}\text { No (\%) } \\
\text { positive tests }\end{array}$ \\
\hline 1986 & 122 & $2 \cdot 9$ & $62(51)$ & $47(39)$ & $13(11)$ & $12 \cdot 2(10 \cdot 0)$ \\
1987 & 213 & $5 \cdot 1$ & $58(27)$ & $144(68)$ & $11(5)$ & $17 \cdot 9(8 \cdot 4)$ \\
1988 & 270 & $6 \cdot 4$ & $58(21)$ & $203(75)$ & $9(3)$ & $20 \cdot 9(7 \cdot 4)$ \\
1989 & 302 & $7 \cdot 1$ & $64(21)$ & $226(75)$ & $12(4)$ & $16 \cdot 8(5 \cdot 6)$ \\
1990 & 320 & $7 \cdot 6$ & $65(20)$ & $254(79)$ & 1 & $15 \cdot 6(4 \cdot 9)$ \\
1991 & 341 & $8 \cdot 0$ & $50(15)$ & $277(81)$ & $14(4)$ & $15 \cdot 5(4 \cdot 5)$ \\
\hline
\end{tabular}

ETA=enzyme immunoassay.

Table 4 Use of chlamydial tests in Vestfold county, 1991

\begin{tabular}{|c|c|c|c|c|c|}
\hline \multirow[b]{2}{*}{ Sex } & \multirow[b]{2}{*}{ Age group (years) } & \multicolumn{2}{|c|}{$\begin{array}{l}\text { Patients tested in random } \\
\text { four week period }\end{array}$} & \multicolumn{2}{|c|}{$\begin{array}{c}\text { Tests per } \\
100 \text { population }\end{array}$} \\
\hline & & $\mathrm{No}(\%)$ & $95 \% C I$ & No & $95 \% C I$ \\
\hline Female & $\begin{array}{c}\leqslant 14 \\
15-19 \\
20-24 \\
25-29 \\
30-34 \\
35-39 \\
\geqslant 40 \\
\text { All ages }\end{array}$ & $\begin{array}{c}8(0 \cdot 9) \\
111(12 \cdot 2) \\
236(25 \cdot 8) \\
197(21 \cdot 6) \\
146(16 \cdot 0) \\
62(6 \cdot 8) \\
88(9 \cdot 6) \\
848(92 \cdot 9)\end{array}$ & $\begin{array}{r}0.2 \text { to } 1.5 \\
10.0 \text { to } 14.3 \\
23.0 \text { to } 28.7 \\
18.9 \text { to } 24.2 \\
13.6 \text { to } 18.4 \\
5.2 \text { to } 8.4 \\
7.7 \text { to } 11.6 \\
91.2 \text { to } 94.5\end{array}$ & $\begin{array}{r}0 \cdot 6 \\
22 \cdot 0 \\
47 \cdot 2 \\
42 \cdot 3 \\
29 \cdot 8 \\
12 \cdot 5 \\
2 \cdot 7 \\
12 \cdot 1\end{array}$ & $\begin{array}{r}0.2 \text { to } 1 \cdot 1 \\
18 \cdot 2 \text { to } 25 \cdot 8 \\
42 \cdot 1 \text { to } 52 \cdot 3 \\
37 \cdot 1 \text { to } 47 \cdot 5 \\
25.4 \text { to } 34.2 \\
9.5 \text { to } 15.5 \\
2.1 \text { to } 3 \cdot 2 \\
10.2 \text { to } 13.9\end{array}$ \\
\hline Male & All ages & $65(7 \cdot 1)$ & 5.5 to 8.8 & $\begin{array}{r}12.1 \\
1.0\end{array}$ & 0.5 to 1.5 \\
\hline Total & & $913(100)$ & & $6 \cdot 6$ & \\
\hline
\end{tabular}

$\mathrm{CI}=$ Confidence interval.

Table 5 Estimated distribution of chlamydial tests in Norwegian population and predictive value of positive enzyme immunoassay. Values are percentages

\begin{tabular}{|c|c|c|c|c|c|c|}
\hline \multirow[b]{2}{*}{ Sex } & \multirow[b]{2}{*}{ Age group (years) } & \multirow[b]{2}{*}{ Distribution } & \multicolumn{2}{|c|}{ Chlamydiazyme } & \multicolumn{2}{|c|}{ Ideia } \\
\hline & & & $P P V$ & $F P R$ & $P P V$ & $F P R$ \\
\hline Female & $\begin{array}{c}<20 \\
20-24 \\
25-29 \\
>29\end{array}$ & $\begin{array}{l}13 \\
26 \\
22 \\
32\end{array}$ & $\begin{array}{l}59 \\
60 \\
39 \\
17\end{array}$ & $\begin{array}{l}41 \\
40 \\
61 \\
83\end{array}$ & $\begin{array}{l}80 \\
81 \\
63 \\
36\end{array}$ & $\begin{array}{l}20 \\
19 \\
37 \\
64\end{array}$ \\
\hline Male & All ages & 7 & & & & \\
\hline
\end{tabular}

$\mathrm{PPV}=$ positive predictive value FFR $=$ false positive rate .

1991, and during the random four week period women accounted for $92.9 \%(848 / 913$; $95 \%$ confidence interval 91.2 to 94.5 ) of all patients tested (table 4). On average almost every second woman in Vestfold aged 20-29 years wes tested.

In Vestfold county the overall testing rate in 1991 was 6.6 per hundred population, which is well below the national average of 8.0 . Applying the sex specific and age specific testing rates of that county (table 4) to the whole nation gives a theoretical total of 294000 tests, which is well below the actual figure of 341000 tests. The national estimates may be based on the Vestfold figures if it is borne in mind that these probably represent lower boundaries of the true national rates.

FALSE POSITIVE RATES

Table 5 shows the positive predictive value and false positive rate for the Ideia and Chlamydiazyme tests in different age groups of women, together with the estimates of the national distribution of tests by age group. About a third of the tests in Norway are performed in circumstances when a positive result will be true in only $17-36 \%$ of the cases. In other words, a third of the positive tests have a probability of $64-83 \%$ of being false positive.

\section{Discussion}

More than $30 \%$ of the GPs did not answer the questionnaire. Possibly GPs who seldom diagnose chlamydial infections may not have responded; these GPs would probably do less routine testing resulting in a biased response.

The laboratories were instructed to report tests on only genital specimens and to count multiple specimens from the same patient as one specimen. Some laboratories were unable to do this. However, the survey in the Vestfold laboratory showed that less than $1 \%$ of the specimens were non-genital and that less than $5 \%$ were multiple specimens.

The prevalence of chlamydial infection in women having a legal abortion is probably higher than in the general female population. Therefore my use of the prevalence of infection in women having an abortion to represent the prevalence in the general population will lead to an underestimation of the false positive rates of the chlamydial tests. The false positive rates presented in table 5 should thus be regarded as minimum rates.

The results show that more than half of all Norwegian GPs have already started screening for chlamydial infection in certain groups of patients; a further quarter are using liberal indications for chlamydial testing. It seems to be customary to obtain samples for chlamydial testing whenever a pelvic examination is performed. If the 3035 GPs in Norway were assumed to perform $90 \%$ of all chlamydial tests each GP performed on average 100 tests in 1991 .

The GPs' routines are reflected in the high age specific testing rates among women. Almost every second woman aged $20-29$ and at least a quarter of women aged 30-34 were tested each year.

This liberal testing policy has developed without any political decision, any official guidelines, or any attempts to address the criteria for screening programmes. $^{12}$ Furthermore, the screening is unsystematic: whether a woman is tested or not depends on her behaviour in seeking health care and her GP's routine practice. The patients who need a chlamydial test may be those who do not receive one - for instance, because they do not see a doctor regularly. This may make screening less efficient in terms of controlling the epidemic and preventing sequelae of chlamydial infection.

Three factors may explain the development of this unofficial screening programme. Firstly, the shift from cell culture techniques to EIAs has revolutionised chlamydial diagnostics. Samples no longer have to be specially transported to the laboratory to conform to the 24 hour limit imposed by the cell culture technique but can be posted. This has enabled many GPs in rural areas to start chlamydial testing. Laboratories that have been reluctant to take up the labour intensive cell culture technique now have the opportunity to analyse large numbers of samples rapidly and easily by EIA. Secondly, a favourable reimbursement system encourages both GPs and laboratories to 
perform many tests. The GPs are reimbursed $£ 2.20$ from the national health insurance for every specimen sent to a laboratory for chlamydial testing. The laboratories receive $£ 7.00$ for every immunoassay they perform. Thirdly, both the public and the medical community have gained more insight into the possible sequelae of genital chlamydial infection. Women may worry about having the disease and are demanding chlamydial tests as part of their regular pelvic examination, and their doctors want to help them to uncover chlamydial infection, to treat it, and thereby to prevent infertility.

Two problems are inherent in an unsystematic screening programme such as that described here. Firstly, in terms of patient care, the use of a test with less than $100 \%$ specificity for screening will inevitably lead to a number of false positive tests. It is the doctors' responsibility to be aware of the limitations of the test and to inform patients of these limitations and the possible consequences of a false positive result. The false positive rate should be declared.

Unfortunately, there are indications that clinicians themselves regard every positive result obtained by EIA as proof of infection. Since 1989 clinicians have reported about 12000 cases of genital chlamydial infection a year to the Norwegian surveillance system for infectious diseases. ${ }^{13}$ This number is consistent with the laboratory reports (table 3 ) when the $35 \%$ of underreporting among clinicians is taken into account. ${ }^{14}$

Thus I conclude that probably hundreds, possibly thousands, of women every year suffer the consequences of false diagnosis of a sexually transmitted disease. The marital and social consequences of diagnosis of a sexually transmitted disease may be formidable. In addition, the diagnosis is often followed by partner notification, ${ }^{10}$ increasing the number of persons affected by the consequences.

Secondly, there is the public health problem of spending a large amount of money on a programme that may not be cost effective. In 1991 the national health insurance spent f3.6m on reimbursements to physicians and laboratories for chlamydial tests; that is up from $£ 1.7 \mathrm{~m}$ in 1986 . The cost per positive test increased from $£ 140$ to $£ 240$.

The ultimate aim of the efforts to control the chlamydial epidemic is to prevent reproductive sequelae in women. Several attempts have been made at estimating the cost effectiveness of routine testing for genital chlamydial infection in women compared with other control strategies. ${ }^{15-18}$ The critical variables of most models are the prevalence of infection in the population and the costs associated with infertility. A Norwegian study reported a threshold prevalence of infection for cost effectiveness at $10-12 \% .{ }^{19}$ However, the models may be criticised for underestimating the costs of chlamydial infections to individual patients. For instance, the emotional stress of infertility is not quantified in the model. Nevertheless, on a purely economic basis it is not justifiable to screen

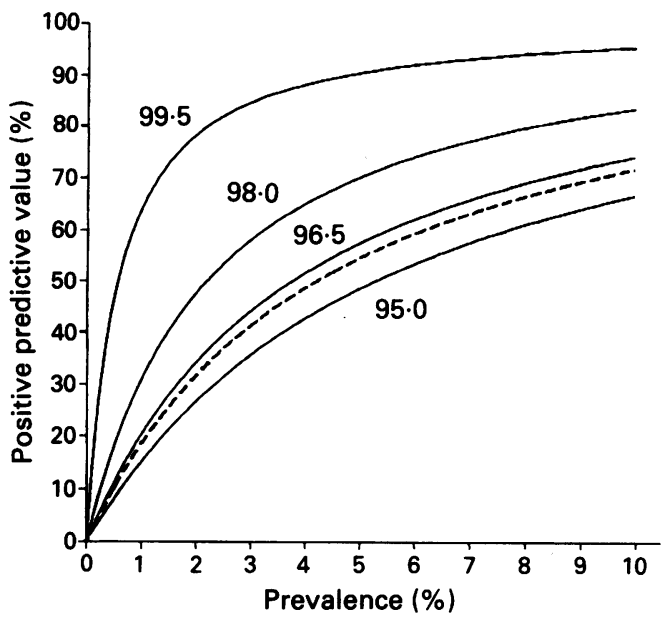

Relation between positive predictive value, prevalence of infection, and specificity (curves) of test at $90 \%$ sensitivity. Minor influence of sensitivity is shown by curve of $80 \%$ sensitivity (broken line) for $96.5 \%$ specificity

asymptomatic Norwegian women of any age group for chlamydial infection.

The solutions to these problems must include the defining of a national screening policy. Its aims should be to reduce the costs; reduce the number of false positive diagnoses or at least their consequences; and to control the epidemic of chlamydial infections.

A graphical illustration of the relation between test performances, prevalence of infection, and positive predictive value (figure) shows two ways of solving the problem of false positive tests. Firstly, testing could be restricted to populations that have a presumed high prevalence of infection. Then even tests with $95 \%$ specificity would be reasonably useful. The populations could be defined not only on the basis of their age but also on other demogaphic or clinical factors. Several investigators have tried to find useful criteria for defining groups that have a high risk of genital chlamydial infection. In the United States age, recent change of partner, cervical friability, and mucopurulent cervicitis are predictors of chlamydial cervicitis. ${ }^{2021}$ However, cultural differences probably prohibit the usefulness of these predictors in populations other than those from which they were derived.

Restricting testing leads of course to the larger issues of patient care and health policy. By restricting testing, some infected patients would inevitably be missed. These patients may also be victims of pelvic inflammatory disease, with possible reproductive sequelae, and they may also transmit chlamydial infection to others. These questions must be addressed openly. The decisions on screening policy cannot be left to individual GPs.

Secondly, the use of tests with a better specificity could be encouraged. A small increase in specificity would greatly enhance the predictive value of a positive test, especially in populations with a low prevalence of infection (figure). Better tests are now available: for the EIAs confirmatory blocking assays have been marketed, ${ }^{22}$ and these will 
increase specificity. However, even a test with a specificity as good as $99.5 \%$ will rapidly lose its positive predictive value in populations with a prevalence of infection below $2 \%$.

Finally, every doctor bears a heavy responsibility for understanding the limitations of diagnostic tests in populations with a low prevalence of infection. This understanding is a prerequisite for good care of their patients.

I thank Arild Bjørndal and Arve Lystad; the National Institute of Public Health; and Kirsti Haaland, Ullevaal Hospital, for critical review of the manuscript. This study was supported by a grant (SAMSOS) from the Directorate of Health.

1 Cates W, Rolfs RT, Aral SO. Sexually transmitted diseases, pelvic inflammatory disease, and infertility: an epidemiologic update. Epidemiol Rev 1990;12:199-220.

2 Cates W, Wasserheit JN. Genital chlamydial infection: epidemiology and reproductive sequelae. Am $\mathcal{F}$ Obstet Gynecol 1991;164:1771-81.

3 Zimmermann HL, Potterat JJ, Dukes RL, Muth JB, Zimmermann HP, Fogle JS, et al. Epidemiologic Zimmermann HP, Fogle JS, et al. Epidemiologic differences between chlamydia
Public Health 1990;80:1338-42.

4 Handsfield HH, Jasman LL, Roberts PL, Hanson VW, Kothenbeutel RL, Stamm WE. Criteria for selective screening for Chlamydia trachomatis infection in women attending family planning clinics. $\mathcal{F} A M A$ 1986;255: $1730-4$.

5 Kellog JA. Clinical and laboratory considerations of culture vs antigen assays for detection of Chlamydia trachomatis from genital specimens. Arch Pathol Lab Med 1989; 113:453-60

6 Barnes RC. Laboratory diagnosis of human chlamydial infections. Clin Microbiol Rev 1989;2:119-36.

7 Taylor-Robinson D, Thomas BJ. Laboratory techniques for the diagnosis of chlamydial infections. Genitourin Med the diagnosis of
8 Nordbø SA, Mehl A, Vik ISS, Ragnhildstveit E. Diagnostikk av Chlamydia trachomatis - dyrkning eller

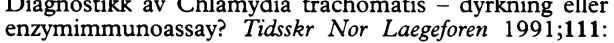
2413-6.

9 Aavitsland P. Survey of the treatment of Chlamydia trachomatis infection of the female genital tract. Acta trachomatis infection of the female gent

10 Mowinckel R, Staurseth JA, Holen P, Aavitsland P. Norske legers rutiner for smitteopposporing ved genitale chlamydiainfeksioner. En spørreundersøkelse. Tidsskr Nor Laegeforen 1992;112:1729-33.

11 Altman DG. Practical statistics for medical research. London: Chapman and Hall, 1991.

12 Edwards PJ, Hall DMB. Screening, ethics, and the law. BMF 1992;305:267-8.

13 Gedde-Dahl TW, Hansen R, Kleivan D, Klingberg MA, Lystad A. A new notification system for infectious diseases in Noway. NIPH Annals 1978;1:43-50.

14 Sinding-Larsen E. Meldedekning - summarisk ukemedling. MSIS Meldesyst Infeksjonssykd 1991;19(50).

15 Nettleman MD, Jones RB. Cost-effectiveness of screening women at moderate risk for genital infections caused by women at moderate risk for genital infections caused

16 Estany A, Todd M, Vasquez M, McLaren RN. Early detection of genital chlamydial infection in women: an economic evaluation. Sex Transm Dis 1989;16:21-7.

17 Weinstock HS, Bolan GA, Kohn R, Balladeres C, Back A, Oliva G. Chlamydia trachomatis infection in women: a need for universal screening in high prevalence populations? Am f Epidemiol 1992;135:41-7.

18 Phillips RS, Aronson MD, Taylor WC, Safran C. Should tests for Chlamydia trachomatis cervical infection be done during routine gynecologic visits? Ann Intern Med 1987;107:188-94.

19 Buhaug H, Skjeldestad FE, Backe B, Dalen A. Cost effectiveness of testing for chlamydial infections in asymptomatic women. Med Care 1989;27:833-41.

20 Handsfield HH, Jasman LL, Roberts PL, Hanson VW, Kothenbeutel RL, Stamm WE. Criteria for selective screening for Chlamydia trachomatis infection in women screening for Chlamydia trachomatis infection in women
attending family planning clinics. $J A M A$ 1986;255:1730-4.

21 Johnson BA, Poses RM, Fortner CA, Meier FA, Dalton HP. Derivation and validation of a clinical diagnostic model for chlamydial cervical infection in university women. $f A M A$ 1990; 264:3161-5.

22 Mills RD, Young A, Cain K, Blair TMH, Sitorious MA, Woods GL. Chlamydiazyme plus blocking assay to detect Chlamydia trachomatis in endocervical specimens. $A m \mathcal{F}$ Clin Pathol 1992;97:209-12. 